\title{
28 Research Square \\ Do Oral Combined Contraceptive Pills Modify Body Image and Sexual Function?
}

Krzysztof Nowosielski ( $\square$ knowosielski@sum.edu.pl )

Medical University of Silesia

\section{Research Article}

Keywords: sexuality, sexual dysfunction, hormonal contraceptive, sexual self-scheme, body image

Posted Date: February 3rd, 2022

DOI: https://doi.org/10.21203/rs.3.rs-1318629/v1

License: (c) (i) This work is licensed under a Creative Commons Attribution 4.0 International License.

Read Full License 


\section{Abstract}

Background. The effect of hormonal contraceptives on sexual function and body image is still controversial. Existing studies have not come to definite conclusion on the associate between hormonal contraceptive use and sexual function/presence of sexual dysfunction nor changes in body image perception. Thus, this study aimed to evaluate the prevalence of sexual problems/dysfunction in Polish women in the reproductive age (18-45 years) and to assess to what extend oral combined contraceptive pills (OCCP) impact body image, sexual function and prevalence of Female Sexual Dysfunction - FSD.

Methods. 495 women were included in this cross-sectional questionnaire-based study. Sexual function was assessed by Changes in Sexual Function Questionnaire - CSFQ, prevalence of FSD by DSM- 5 criteria and body image by Body Exposure during Sexual Activity Questionnaire (BESAQ). 237 women using OCCP were study group ( $\mathrm{HC}$ ), the rest were controls (CG). Regression model was used to evaluate the influence of selected variable on sexual function and the presence of FSD.

Results. The prevalence of FSD was $7.5 \%$ in $\mathrm{HC}$ and $2.6 \%$ in CG. $22 \%$ compared to $14 \%$ of women in $\mathrm{HC}$ and CG, respectively, reported sexual problems (CSFQ). Contraceptive group was characterized by significantly higher importance of sex (4.03 vs 3.79), worse partner's' attitude toward sex (4.35 vs 4.47), worse self-attitude towards sex (4.35 vs 4.47), and worse body image (BESAQ) compared to controls. Among all variables lower level of anxiety $(t=-1.99)$, positive attitudes toward sex $(t=2.05)$, watching erotic videos $(t=5.58)$ and higher importance of sex $(t=5.66)$ were predictive for better sexual function ( 2 $0.38, F=28.9, p=0.0001)$.

Conclusion. Sexual behaviors and function are different in those using OCCP's compared to non-users. The prevalence of sexual problems and dysfunction is higher in those using hormonal method, however using OCCP is not a risk factor for neither worse sexual function nor sexual dysfunction. Partner's attitude toward sex and general anxiety level are factors contributing to sexual function and risk of sexual dysfunction in the population of women in reproductive age and should be routinely evaluated in clinical practice, especially before prescribing hormonal contraceptives.

\section{Background}

According to the latest statement by European Society for Sexual Medicine "The effects of hormonal contraceptives on sexual function have not been well studied and remain controversial"(1). The influence of that contraceptives is definitely complex as complexed is woman sexuality. There are numerous factors influencing sexual response from testosterone level in brain and erogenic tissues, through activation of b-adrenergic receptors in vaginal epithelial cells and effectiveness of aquaporins (2-5) to recently addressed androgen receptor polymorphism (CAG repeats length) (6-8). However, none of that biological variables might have the dominant influence on sexual functioning as other psychological, social and partner-related components play unquestionable role (as showed in our other studies, e.g. in menopausal women) (9). 
It is well proven that serum androgen level declines with age (10) and that hormonal contraceptives increases the level of Sex Hormone Binding Globulin (SHGB) what leads to decrease in free Testosterone (fT) level (11). However, direct effect of that reduction of circulation androgens on sexual function has not been showed either in observational studies (12) or interventional one (13). Similarly, no effect or positive influence was noticed in long-lasting reversible contraceptives methods (14). Neither any administration route (15) nor four-phasic agent (16) seemed to be superior.

As the results of available studies are conflicting showing a negative (decreased libido, arousal and orgasm, increase pain) (17-19) or positive influence/no effect $(1,14,20,21)$, further studies are needed. Some new light was brought by a paper by Wåhlin-Jacobsen et al. [8] showing that number of CAG repeats in androgen receptors might play a role - longer repeats are associated with receptors more prone to changes in fT levels - thus women with longer repeats could be more sensitive to changes in androgens due to use of hormonal contraception. However, that dependency might not be linear but rathe "bell" shaped. In that context new well-designed studies with strict criteria for sexual dysfunction and function assessments are needed to picture the real associations.

The study aimed to answer the following questions. Firstly, what is the prevalence of sexual problems and sexual dysfunction based on DSM-5 criteria in the population of Polish women in the reproductive age (18-45 years)? Secondly, to what extend oral combined contraceptive pills (OCCP) influences sexual function (assessed by Changes in Sexual Function Questionnaire - CSFQ) and prevalence of Female Sexual Dysfunction - FSD (DSM-5 criteria). Thirdly, what are the factors influencing the prevalence of FSD (DSM-5 criteria) and sexual function (assessed by CSFQ) in the general population of women in the reproductive age and in those using ОССP? Fourthly, how, in subjective opinion of women, ОCCP influences sexual function. And finally, does dose, gestagen type, and regimen influence sexual function in women on hormonal contraception?

\section{Methods}

A total number of 1004 women in the reproduction age (18-45 years) were eligible for this cross-sectional study conducted between $1^{\text {st }}$ March 20218 and $31^{\text {st }}$ December 2020. The patients were recruited from among those being appointed for routine gynecological yearly check-up visit and via internet (Facebook funpage). All were handed in a link to the online version of the questionnaire (based on www.surveymonkey.com page) and were asked to fill it in at home. No identification data were required. However, all participants had to mark "Yes" answer to agree to participate in this study.

The inclusion criteria were being in the reproductive age between 18 and 45 years old and agreeing to participate in the study. Women diagnosed with cancer or being treated for any cancer in last 5 years, with severe cardiac insufficiency, less than 6 months after myocardial infarction, with unstable heart disease and unstable arterial hypertension, in pregnancy or lactating, with history of psychiatric disorders or currently on antidepressants, with overactive bladder, prolapse of the vaginal vault more than grade 2 , stress urinary incontinence, and who had never have vaginal/anal/oral sex were excluded from the study. 
From all eligible women 619 fill the questioner in - the response rate was $61.6 \%$. Out of those 43 were being treated for psychiatric disorder (depression), 11 were lactating, 37 had fil in only the first page with demographic data, and 33 scored ${ }^{3} 11$ points in Hospital Depression and Anxiety Scale (HADS) scale what was indicative for depressive symptoms. 495 individuals were included to the final analysis - Figure 1.

The study participants were divided in two groups: those using OCCP's (HC group) and those using other methods or not using any (control group - CG).

The questioner used in the study contained general medical history questions, demographic and socioeconomic one, and the battery of standardizes and validated scales. Changes in Sexual Function Questionnaire (CSFQ) was used to assess sexual function - scoring less that 41 point were indicative for sexual problems (9). Based on Diagnostic and Statistical Manual of Mental Disorders, 5th Edition (DSM5) criteria five questions were used to assess FSD (22). HADS were used for assessing general anxiety level and depressive symptoms. Body Exposure during Sexual Activity Questionnaire (BESAQ) were used for body image and sexual avoidance assessment (23). Sexual satisfaction, attitudes toward sex, importance of sex, relationship quality, satisfaction from a partner as a lover, sexual life quality were assessed by a single 5-point Liker scale-based questions. Finally, sexual self-schemas were evaluated by Sexual Self-Schema Scale $(24,25)$. The detailed description of all used scale may be found in our previous studies $(9,22-24)$. Additionally, all women using contraception were asked if hormonal methods influence their sexual function and for brand name and regimen of OCCP. Based on that information the dose of estrogens and gestagen generation were identified. Additionally, tape and frequency of sexual activities were evaluated.

Risky sexual behaviors (RBS) was defined as "sexual contacts with more than one sexual partner at the same time, engaging in sexual activity with a casual person (one-night stand), frequent change of sexual partners, having intercourse with a person living with HIV, inconsistent use of condoms in oral, anal, and vaginal contacts except within the current relationship, prostitution or using the services of an escort agency, sexual contacts under the influence of psychoactive substances other than alcohol and marijuana, (chemsex) and drug injection with shared needles within the last 6 months" (9).

The study protocol was approved by the Ethical Committee of the Silesian Chamber of Physicians and Dentists in Katowice, Poland (decision number - ŚIL:/KB/755p/15).

Study sample calculation. According to Statistical books in Poland in $20198,943,200$ women were in reproductive age. Based on the assumption a minima sample of 386 individuals was required, with $95 \%$ Confidence level $(\mathrm{Cl})$ and $5 \%$ margin of error. Additionally, assuming that the prevalence of FSD based on DSM-5 criteria in Poland would be 15\% (22) the minima required sample would be 454 with $\mathrm{Cl} 95 \%$ and margin of error $3 \%$. As at least $20 \%$ will be lost (returning empty questionnaires), the initial sample should be at least 544 women. Furthermore, the sample size of 425 was required to detect a difference at least 0.3 between means in CSFQ, with the pawer of $80 \%$ and margin of error $-5 \%$. Finally, post-hoc analyses showed that the study had a power of $75 \%(a=0.05)$ to detect the difference of $4.9 \%$ between groups in the prevalence of FSD (DSM-5) 
Statistical analysis was performed in Statistica 12.0 for Windows (StatSoft, Warsaw, Poland). Missing values were assessed for all variables (less than $5 \%$ ). "Skewness and kurtosis was assessed to check for univariate and multivariate distribution normality. Values larger than 3 for skewness or larger than 10 for kurtosis were considered to indicate nonnormality" (22). To assess factors influencing sexual function (based ion CSFQ) and frequency of sexual dysfunction (DSM-5 criteria) univariate linear and logistic regression models were used. In the first step, all variables were checked for significant contribution to assessed parameters. In the final step, only those statistically significant in the first step were introduced to the model - multivariate forward stepwise regression. The final models were established. P-values less than 0.05 served as statistically significant.

\section{Results}

The mean age of the studied population was $29.2 \pm 7.2(18.0-45.8)$ years old. 237 women were using OCCP's, 124 (25.0\%) were using non-hormonal methods and $135(27.3 \%)$ have not used any contraception.

In non-hormonal group 11.3\% $(n=14)$ had non-hormonal IUD, $24.1 \quad(n=30)$ were using natural planning methods, $24.1 \%(n=30)$ - condoms, and $42.7 \%(n=52)$ were using withdrawal (not a contraceptive method in Europe, but still used in Poland).

The analysis of the type of OCCP's showed that $50.3 \%$ (79\%) were using contraceptives containing IV generation of gestagens, $21.0 \%(n=33)$ - III generation, $22.9 \%(36)$ - I generation, and $5.7 \%(n=9)-$ II generation. The most dominant proportion of women used 30 and 20 ug of estrogens $-47.0 \%$ and $46.4 \%$, respectively, with $21+7$ regimen being most prevalent - used by $83.3 \%$ of women.

The comparison of CG and HC group showed that CG had higher proportion of women who declared excessive alcohol consumption defined as mere that one standard glass of vine, one big bear or $50 \mathrm{ml}$ of alcohol daily (61.5\% vs $38.5 \%$ ), who have never had oral sex ( $80.6 \%$ vs $63.7 \%)$, were less sexually active in last 6 month (91.5\% vs $97.9 \%$ ), has less regular menses $75.6 \%$ vs $88.6 \%$ ), and higher religiosity (2.66 vs 2.44) compared to HC group. Contraceptive group was characterized by significantly higher $\mathrm{nr}$ of deliveries, higher importance of sex (4.03 vs 3.79 ), worse partner's' attitude toward sex (4.35 vs 4.47), worse self-attitude towards sex (4.35 vs 4.47) compared to controls - Table 1 and 2.

The analysis of sexual behaviors, functions, problems and dysfunction reveled that $\mathrm{HC}$ group had higher frequency of vaginal sex, lower of oral sex, higher self-masturbation, better orgasm/completion but lower arousal/excitement function (based on CSFQ), lower proportion of sexual negative and co-schematic and higher of negative schematic women, and worse body image (higher sexual avoidance based on BESAQ) - Table 1 and 2.

Sexual dysfunction was diagnosed (DSM-5) in 21 women (5.1\%). That prevalence was higher in those using hormonal contraceptive compared to controls ( $7.5 \%$ vs $2.6 \%$ ). However, the difference was only 
found in case of pain during sexual acts (5.7\% vs $1.9 \%)$. There was no difference in the presence of sexual distress.

Sexual problems (based on CSFQ) were noted in 17.1\% $(n=52)$ of studied women. The prevalence of such problems was higher in $\mathrm{HC}$ group compared to controls. Low pleasure, low arousal/excitement and low orgasm/completion were more prevalent in hormonal contraception group - Table 1.

Additionally, when asked for subjective opinion, no changes or slightly decrease (except pain that slightly increased) were noted in women using hormonal methods - Figure 2.

Finally, the analysis of factors influencing sexual function and dysfunction was evaluated in logistic model. The results showed that among all variables lower level of anxiety ( $t=-1.99)$, positive attitudes toward sex $(t=2.05)$, being schematic positive $(t=-2.92)$, watching erotic videos $(t=5.58)$ and higher importance of sex $(t=5.66)$ were predictive for better sexual function (corrected R2 $-0.38, F=28.9$, $\mathrm{p}=0.0001$ ). Using OCCP's has not entered the model. In case of similar analysis but in women using OCCP's, similar factors were identified: positive attitudes toward sex $(t=2.43)$, being schematic positive $(t=-3.12)$, watching erotic videos $(t=4.21)$ and higher importance of sex $(t=3.42)$ were predictive for better sexual function (corrected R2 $-0.35, F=20.1, p=0.0001$ ). Neither gestagen generation, estrogen dose, regimen, nor duration of use has not influenced sexual function. Further logistic regression model showed two risk factors of sexual dysfunction (DSM-5) in general population and three in HC group: worse partner's attitude toward sex $(\mathrm{OR}=0.23 ; \mathrm{Cl}: 0.1-0.55 ; \mathrm{p}=0.01)$, and higher level of general anxiety $(\mathrm{OR}=1.36$; $\mathrm{Cl}: 1.01-1.69 ; \mathrm{p}=0.01)$, as well as lower satisfaction from a partner as a lover ( $\mathrm{OR}=0.09 ; \mathrm{Cl}: 0.01-0.22$; $p=0.02)$, worse partner's attitude toward sex $(O R=0.16 ; \mathrm{Cl}: 0.03-0.94 ; p=0.04)$, and higher level of general anxiety $(\mathrm{OR}=1.61 ; \mathrm{Cl}: 1.06-2.43 ; \mathrm{p}=0.02)$, respectively. Neither using OCCP's, nor none of contraception relative factors has entered the model.

\section{Discussion}

To our knowledge this is one of the first papers that used strict DSM-5 criteria to assess the prevalence of sexual dysfunction in the Polish population of women in the reproductive age especially those using OCCP's. Additionally, partner-related factors, sexual self-schemas and body avoidance were also evaluated picturing multidimensional dependencies in regulation of sexual function in that group of women. The results might serve as a background for discission on implementing of anxiety, body image and attitudes toward sex evaluation when consulting women before starting hormonal contraceptives.

Based on the study result the prevalence of FSD in general population was $5.1 \%$ and in those using OCCP's $-7.5 \%$. That prevalence was much lower compared to our previous studies in general population $-14.7 \%$ (22); however, women in the present report were younger (mean age 29 vs 39, respectively), what might influence the results. Similar proportion of FSD but based of Female Sexual Function Index (FSFI) was presented in Finish report (21). No previous studies have evaluated FSD based on DSM-5 criteria. 
The recent metanalysis of studies on hormonal contraceptives and sexual dysfunction reported that based on FSFI scores up to $36.7 \%$ of hormonal contraceptive users reported some sexual problems (17, 26). That is in line with our results showing that $22 \%$ of users reported sexual problems. When analysis the prevalence of disturbances in particular domain, the numbers were much higher; however, that has to be interpreted with caution, as the scale might not be suitable for assessing the sexual problems and FSFI might be better screening tool (20).

Some differences were also noted between users and non-users in sexual behaviors - those in HC group were more frequently sexually active, had more vaginal sex a month but had lower frequency of orgasm. That is in line with other studies showing fewer orgasm $(t=-2.39, P<0.05)$, but higher rate of lubrication problems $(t=2.00, P<0.05)$, and lower frequency of pleasure $(-1.95, P<0.05)$, with no differences in pain (in contrast to our study results) (19). Despite aforementioned differences in users and non-users regression model showed no influence of hormonal contraceptives on neither sexual function nor prevalence of dysfunction. That is similar to recently published summary of conducted studies reporting increase or no change in desire, decrease orgasm frequency (except Mirena users), or no impact on vulvovaginal symptoms or lubrication $(1,20,21)$. No effect on estrogens dose or regimen, similar to our study, was also noted in other papiers (27). In contrast, some papers showed increase likelihood of worsening sexual desire $(\mathrm{OR}=2.47)$, arousal $(\mathrm{OR}=2.85)$ and sexual function in general $(\mathrm{OR}=2.01)$ assessed by FSFI after 3 months of using Drospirenon containing oral contraceptives $(20,28)$. However, the population induced in the study was small to draw the definite conclusion. Some differences might be also due to cultural script and ethnicity - women from Europe seems to have higher prevalence of pain during intercourse when using hormonal contraceptives compared to other continents (20)

When asked about subjective opinion on the influence of hormonal contraceptives women declared no effect or slightly decrease in sexual response, what is in line with some previous observation - no effect in $55 \%$ of users (29).

Finally, some other factors were important in predicting sexual function and the risk of dysfunction, namely anxiety level, watching erotic videos, importance of sex, and partners attitude toward sex. It seems, like presented in Rausch and Rettenberger recent paper, that partner-related factors might play a major role (30). Similarly, erotic material(30), importance of sexual acts (31) in a positive way and anxiety in negative (32) were also reported to be predictive by other authors.

It has to be underlined that, undoubtedly, hormonal contraceptives might influence some aspect of sexuality like might change the perception of partners attractiveness thus modifies the sexual receptivity or change the concentration of oxytocin during sexual cycle $(1,33)$. However, the extent to what sexuality might be modified seems to be more complexed and depend on genetic and partner-related factors (having a partner, attitude toward sex) factors $(31,34)$. In that light an afford has to be made in consulting women before introducing contraceptive or when sexual dysfunction emerges during hormonal conceptive uses. Changing the contraceptive preparation (13) or, if indicated, adding androgens (35) might be an option. However, education intervention and anxiety reduction may be better alternative. 
The paper has also some limitation. Firstly, sexual satisfaction and relationship quality were assessed by one single question. However, similar methodology was used in other studies and is generally accepted (36). Secondly, propensity for inhibition/excitation could also be evaluated, what is currently being pain more and more attention (22). Thirdly, we have not evaluated the effect of progestin-only pills (POP), hormonal IUD, patches, ringd and injections, like in Hassanin et al study where $95 \%$ and $84 \%$ of injectable contraceptive and POP users reported decline in sexual function (29). Finally, a prospective character of the study with sexual function evaluation before introducing the hormonal contraceptive would be more reliable in showing the association. Although all that limitation, a large $\mathrm{nr}$ of participant and validated instruments used in the study makes it a valuable contribution to current knowledge of hormonal contraceptives' effect on sexuality.

\section{Conclusions}

Sexual behaviors and function are different in those using hormonal contraceptives compared to nonusers. The prevalence of sexual problems and dysfunction is higher in those using hormonal method, however using hormonal contraceptives is not a risk factor for neither worse sexual function nor sexual dysfunction. Partner's attitude toward sex and general anxiety level are factors contributing to sexual function and risk of sexual dysfunction in the population of women in reproductive age and should be routinely evaluated in clinical practice, especially before prescribing hormonal contraceptives.

\section{List Of Abbreviations}

OCCP - oral combined contraceptive pill, RS - relationship, RSB - Risky Sexual Behaviors, WSW woman who have sex with woman; WSM - woman who has sex with man, WSWM - woman who has sex with woman and man; CSFQ - Changes in Sexual Function Questionnaire, FSD - Female Sexual Dysfunction, FISAD - Female Sexual Interest/Arousal Disorder, FOD - Female Orgasmic Disorder, GPPPD - Genito-Pelvic Pain/Penetration Disorder, HADS - Hospital Anxiety and Depression Scale.

\section{Declarations}

\section{Ethics approval and consent to participate}

The study protocol was approved by the Ethical Committee of the Silesian Chamber of Physicians and Dentists in Katowice, Poland (decision number - ŚlL:/KB/755p/15).

Consent for publication - Not applicable

\section{Availability of data and materials}

The datasets used and/or analyzed during the current study are available from the corresponding author on reasonable request 


\section{Competing interests}

The author declares that he has no competing interests

Funding - This research received no external funding.

\section{Authors' contributions}

Conceptualization - $\mathrm{KN}$; methodology - $\mathrm{KN}$; formal analysis - $\mathrm{KN}$; investigation, writing-original draft preparation $-\mathrm{KN}$; writing $-\mathrm{KN}$; review and editing $-\mathrm{KN}$.

Acknowledgements - none

\section{References}

1. Both S, Lew-Starowicz M, Luria M, Sartorius G, Maseroli E, Tripodi F, et al. Hormonal Contraception and Female Sexuality: Position Statements from the European Society of Sexual Medicine (ESSM). J Sex Med. 2019;16(11):1681-95.

2. Traish AM, Botchevar E, Kim NN. Biochemical factors modulating female genital sexual arousal physiology. J Sex Med. 2010;7(9):2925-46.

3. Levin RJ, Both S, Georgiadis J, Kukkonen T, Park K, Yang CC. The Physiology of Female Sexual Function and the Pathophysiology of Female Sexual Dysfunction (Committee 13A). J Sex Med. 2016;13(5):733-59.

4. Sun Q, Huang J, Yang DL, Cao XN, Zhou WL. Activation of $\beta$-adrenergic receptors during sexual arousal facilitates vaginal lubrication by regulating vaginal epithelial $\mathrm{Cl}(-)$ secretion. J Sex Med. 2014;11(8):1936-48.

5. Zhang H, Liu T, Zhou Z, Zhang A, Zhu Y, Zhang J, et al. miR-137 Affects Vaginal Lubrication in Female Sexual Dysfunction by Targeting Aquaporin-2. Sex Med. 2018;6(4):339-47.

6. Elaut E, Buysse A, De Sutter P, De Cuypere G, Gerris J, Deschepper E, et al. Relation of androgen receptor sensitivity and mood to sexual desire in hormonal contraception users. Contraception. 2012;85(5):470-9.

7. Goldstein AT, Belkin ZR, Krapf JM, Song W, Khera M, Jutrzonka SL, et al. Polymorphisms of the androgen receptor gene and hormonal contraceptive induced provoked vestibulodynia. J Sex Med. 2014;11(11):2764-71.

8. Wåhlin-Jacobsen S, Flanagan JN, Pedersen AT, Kristensen E, Arver S, Giraldi A. Androgen Receptor Polymorphism and Female Sexual Function and Desire. J Sex Med. 2018;15(11):1537-46.

9. Nowosielski K, Sidorowicz M. Sexual behaviors and function during menopausal transition-does menopausal hormonal therapy play a role? Menopause. 2020;28(3):271-83.

10. Guay A, Munarriz R, Jacobson J, Talakoub L, Traish A, Quirk F, et al. Serum androgen levels in healthy premenopausal women with and without sexual dysfunction: Part A. Serum androgen levels in 
women aged 20-49 years with no complaints of sexual dysfunction. Int J Impot Res. 2004;16(2):11220.

11. Zimmerman Y, Eijkemans MJ, Coelingh Bennink HJ, Blankenstein MA, Fauser BC. The effect of combined oral contraception on testosterone levels in healthy women: a systematic review and metaanalysis. Hum Reprod Update. 2014;20(1):76-105.

12. Graham CA, Bancroft J, Doll HA, Greco T, Tanner A. Does oral contraceptive-induced reduction in free testosterone adversely affect the sexuality or mood of women? Psychoneuroendocrinology. 2007;32(3):246-55.

13. Davis SR, Bitzer J, Giraldi A, Palacios S, Parke S, Serrani M, et al. Change to either a nonandrogenic or androgenic progestin-containing oral contraceptive preparation is associated with improved sexual function in women with oral contraceptive-associated sexual dysfunction. J Sex Med. 2013;10(12):3069-79.

14. Sanders JN, Smith NK, Higgins JA. The intimate link: a systematic review of highly effective reversible contraception and women's sexual experience. Clin Obstet Gynecol. 2014;57(4):777-89.

15. Guida M, Cibarelli F, Troisi J, Gallo A, Palumbo AR, Di Spiezio Sardo A. Sexual life impact evaluation of different hormonal contraceptives on the basis of their methods of administration. Arch Gynecol Obstet. 2014;290(6):1239-47.

16. Caruso S, Agnello C, Romano M, Cianci S, Lo Presti L, Malandrino C, et al. Preliminary study on the effect of four-phasic estradiol valerate and dienogest (E2V/DNG) oral contraceptive on the quality of sexual life. J Sex Med. 2011;8(10):2841-50.

17. Panzer C, Guay AT, Goldstein I. Do Oral Contraceptives Produce Irreversible Effects on Women's Sexuality?: A reply. The Journal of Sexual Medicine. 2006;3(3):568-70.

18. Battaglia C, Battaglia B, Mancini F, Busacchi P, Paganotto MC, Morotti E, et al. Sexual behavior and oral contraception: a pilot study. J Sex Med. 2012;9(2):550-7.

19. Smith NK, Jozkowski KN, Sanders SA. Hormonal contraception and female pain, orgasm and sexual pleasure. J Sex Med. 2014;11(2):462-70.

20. Huang M, Li G, Liu J, Li Y, Du P. Is There an Association Between Contraception and Sexual Dysfunction in Women? A Systematic Review and Meta-analysis Based on Female Sexual Function Index. J Sex Med. 2020;17(10):1942-55.

21. Witting K, Santtila P, Jern P, Varjonen M, Wager I, Höglund M, et al. Evaluation of the female sexual function index in a population based sample from Finland. Arch Sex Behav. 2008;37(6):912-24.

22. Nowosielski K, Kurpisz J, Kowalczyk R. Sexual inhibition and sexual excitation in a sample of Polish women. PLoS One. 2021;16(4):e0249560.

23. Nowosielski K, Kurpisz J, Kowalczyk R. Body image during sexual activity in the population of Polish adult women. Prz Menopauzalny. 2019;18(4):198-209.

24. Nowosielski K, Kurpisz J, Kowalczyk R. Sexual self-schema: a cognitive schema and its relationship to choice of contraceptive method among Polish women. Eur J Contracept Reprod Health Care. 2019;24(4):280-7. 
25. Nowosielski K, Jankowski KS, Kowalczyk R, Kurpisz J, Normantowicz-Zakrzewska M, Krasowska A. Sexual Self-Schema Scale for Women-Validation and Psychometric Properties of the Polish Version. Sex Med. 2018;6(2):131-42.

26. Skrzypulec V, Drosdzol A. Evaluation of quality of life and sexual functioning of women using levonorgestrel-releasing intrauterine contraceptive system-Mirena. Coll Antropol. 2008;32: 1059-68.

27. Wallwiener CW, Wallwiener LM, Seeger H, Schönfisch B, Mueck AO, Bitzer J, et al. Are hormonal components of oral contraceptives associated with impaired female sexual function? A questionnaire-based online survey of medical students in Germany, Austria, and Switzerland. Arch Gynecol Obstet. 2015;292(4):883-90.

28. Čiaplinskienè L, Žilaitienė B, Verkauskienè R, Žalinkevičius R, Bumbulienè Ž, Vanagienè V, et al. The effect of a drospirenone-containing combined oral contraceptive on female sexual function: a prospective randomised study. Eur J Contracept Reprod Health Care. 2016;21(5):395-400.

29. Hassanin AM, El-Halwagy AM, Ismail NN, Shehab BA. A Study of the Impact of the Commonly Used Female Contraceptive Methods in Egypt on Female Sexual Function. J Sex Marital Ther. 2018;44(6):605-12.

30. Rausch D, Rettenberger M. Predictors of Sexual Satisfaction in Women: A Systematic Review. Sex Med Rev. 2021;9(3):365-80.

31. Casado-Espada NM, de Alarcón R, de la Iglesia-Larrad JI, Bote-Bonaechea B, Montejo Á. Hormonal Contraceptives, Female Sexual Dysfunction, and Managing Strategies: A Review. J Clin Med. 2019;8(6).

32. Basson R, Gilks T. Women's sexual dysfunction associated with psychiatric disorders and their treatment. Womens Health (Lond). 2018;14:1745506518762664.

33. Nowosielski K, Stolorz K. Contraception and sexuality - between neurobiology and genetics. Psychiatria po Dyplomie. 2016(04):33-47.

34. Caruso S, Agnello C, Malandrino C, Lo Presti L, Cicero C, Cianci S. Do hormones influence women's sex? Sexual activity over the menstrual cycle. J Sex Med. 2014;11(1):211-21.

35. van Rooij K, Poels S, Worst P, Bloemers J, Koppeschaar H, Goldstein A, et al. Efficacy of testosterone combined with a PDE5 inhibitor and testosterone combined with a serotonin (1A) receptor agonist in women with SSRI-induced sexual dysfunction. A preliminary study. Eur J Pharmacol. 2015;753:24651.

36. Eder SJ, Nicholson AA, Stefanczyk MM, Pieniak M, Martínez-Molina J, Pešout O, et al. Securing Your Relationship: Quality of Intimate Relationships During the COVID-19 Pandemic Can Be Predicted by Attachment Style. Front Psychol. 2021;12:647956.

\section{Tables}

Table 1. General characteristic of studied population - qualitative variables. 


\begin{tabular}{|c|c|c|c|}
\hline Variable & Hormonal contraception & Controls & $P^{*}$ \\
\hline \multicolumn{4}{|l|}{ Residency } \\
\hline Urban & $88.2(209)$ & $87.6(226)$ & \multirow[t]{2}{*}{0.88} \\
\hline Rural & $11.8(28)$ & $12.4(32)$ & \\
\hline \multicolumn{4}{|l|}{ Education } \\
\hline Primary & $0.4(1)$ & $1.56(40)$ & \multirow[t]{3}{*}{0.18} \\
\hline Secondary & $34.7(82)$ & $40.1(103)$ & \\
\hline Higher & $64.8(153)$ & $58.4(150)$ & \\
\hline \multicolumn{4}{|l|}{ Education } \\
\hline Black-collar & $9.3(22)$ & $4.4(37)$ & \multirow[t]{3}{*}{0.11} \\
\hline White-collar & $62.4(148)$ & $58.9(151)$ & \\
\hline Unemployed & $28.3(67)$ & $26.6(68)$ & \\
\hline Smoking (Yes) & $18.6(44)$ & $17.8(46)$ & 0.82 \\
\hline Drugs (Yes) & $10.1(24)$ & $9.3(24)$ & 0.75 \\
\hline Alcohol (Yes) & $38.5(62)$ & $61.5(99)$ & 0.004 \\
\hline \multicolumn{4}{|l|}{ Religion } \\
\hline Catholic & $44.6(138)$ & $55.3(171)$ & \multirow[t]{3}{*}{0.85} \\
\hline Other & $39.5(17)$ & $60.5(26)$ & \\
\hline Atheist & $57.4(81)$ & $42.5(60)$ & \\
\hline Participation in religious practices (yes) & $45.3(62)$ & $54.7(76)$ & 0.47 \\
\hline Sexual initiation - oral sex (Yes) & $63,7(151)$ & $80.6(208)$ & 0.0001 \\
\hline Sexual initiation - masturbation (Yes) & $70.0(166)$ & $74.8(193)$ & 0.23 \\
\hline Being in RS (Yes) & $81.4(192)$ & $78.7(203)$ & 0.44 \\
\hline Having sexual partner (Yes) & $89.0(211)$ & $85.7(221)$ & 0.31 \\
\hline Sexual activity in last 6 months (Yes) & $97.9(232)$ & $91.5(236)$ & 0.01 \\
\hline Watching erotic videos (Yes) & $59.9(142)$ & $57.5(111)$ & 0.68 \\
\hline Sexual abuse in childhood (Yes) & $5.5(13)$ & $5.2(10)$ & 0.89 \\
\hline \multicolumn{4}{|l|}{ Sexual behaviors } \\
\hline WSW & $0.4(1)$ & $2.4(4)$ & 0.14 \\
\hline
\end{tabular}




\begin{tabular}{|c|c|c|c|}
\hline WSWM & $13.9(33)$ & $13.7(23)$ & \\
\hline WSM & $85.7(203)$ & $83.9(141)$ & \\
\hline \multicolumn{4}{|l|}{ Sexual orientation } \\
\hline Heterosexual & $86.1(204)$ & $83.3(140)$ & \multirow[t]{5}{*}{0.29} \\
\hline Homosexual & $0.4(1)$ & $1.2(2)$ & \\
\hline Bisexual & $13.5(32)$ & $14.3(24)$ & \\
\hline Asexual & $0(0)$ & $1.2(2)$ & \\
\hline RSB (Yes) & $49.4(117)$ & $36.8(95)$ & \\
\hline Regularity of menstruation (Yes) & $88.6(210)$ & $75.6(127)$ & 0.001 \\
\hline Pregnancies (Yes) & $32.1(76)$ & $32.7(55)$ & 0.88 \\
\hline Miscarriages (Yes) & $1.3(3)$ & $1.9(5)$ & 0.81 \\
\hline Sexual distress - DSM-5 (Yes) & $17.7(40)$ & $13.1(20)$ & 0.22 \\
\hline FSIAD - DSM-5 (Yes) & $1.8(4)$ & $1.31(2)$ & 0.94 \\
\hline FOD - DSM-5 (Yes) & $1.3(3)$ & $0.6(1)$ & 0.91 \\
\hline GPPPD - DSM-5 (Yes) & $5.7(13)$ & $1.9(3)$ & 0.04 \\
\hline Lack of sexual satisfaction (Yes) & $1.3(3)$ & $0.6(1)$ & 0.91 \\
\hline FSD - DSM-5 (Yes) & $7.5(17)$ & $2.6(4)$ & 0.03 \\
\hline HADS - anxiety & $9.4(20)$ & $14.5(20)$ & 0.10 \\
\hline Sexual problems - CSFQ & $22.2(26)$ & $13.9(26)$ & 0.04 \\
\hline Pleasure - CSFQ & $81.3(152)$ & $68.4(80)$ & 0.01 \\
\hline Desire/Frequency - CSFQ & $19.8(37)$ & $35.9(42)$ & 0.01 \\
\hline Desire/Interest - CSFQ & $33.6(63)$ & $41.0(48)$ & 0.24 \\
\hline Arousal/Excitement - CSFQ & $89.8(163)$ & $79.5(93)$ & 0.02 \\
\hline Orgasm/Completion - CSFQ & $62.6(117)$ & $45.3(53)$ & 0.01 \\
\hline Sexual self-Schema - positive & $26.4(43)$ & $37.1(36)$ & 0.04 \\
\hline Sexual self-Schema - negative & $36.2(59)$ & $17.5(17)$ & 0.001 \\
\hline Sexual self-Schema - A-schematic & $14.7(24)$ & $10.3(10)$ & 0.2 \\
\hline Sexual self-Schema - Co-schematic & $22.7(37)$ & $35.1(34)$ & 0.04 \\
\hline
\end{tabular}


* - Chi squared test, RS - relationship, RSB - Risky Sexual Behaviors, WSW - woman who have sex with woman; WSM - woman who has sex with man, WSWM - woman who has sex with woman and man; CSFQ - Changes in Sexual Function Questionnaire, FSD - Female Sexual Dysfunction, FISAD - Female Sexual Interest/Arousal Disorder, FOD - Female Orgasmic Disorder, GPPPD - Genito-Pelvic Pain/Penetration Disorder, HADS - Hospital Anxiety and Depression Scale.

Table 2. General characteristic of studied population - quantitative variables. 


\begin{tabular}{|c|c|c|c|}
\hline Variable & Controls & Hormonal contraception & $P^{*}$ \\
\hline Age & $\begin{array}{l}28.79(17.78- \\
45.84) \pm 7.35\end{array}$ & $29.59(19.34-45.65) \pm 6.95$ & 0.10 \\
\hline $\mathrm{Nr}$ of cigarettes a day & $7.50(0.00-20.00) \pm 6.58$ & $6.82(0.00-20.00) \pm 4.18$ & 0.59 \\
\hline BMI & $\begin{array}{l}22.50(15.94- \\
36.44) \pm 3.43\end{array}$ & $22.59(17.01-29.74) \pm 2.58$ & 0.14 \\
\hline Religiosity & $2.66(1.00-5.00) \pm 1.18$ & $2.44(1.00-5.00) \pm 1.14$ & 0.04 \\
\hline Feeling physically attractive & $3.29(1.00-5.00) \pm 0.99$ & $3.40(1.00-5.00) \pm 0.92$ & 0.23 \\
\hline Vaginal sex & $1.04(1.00-2.00) \pm 0.20$ & $1.00(1.00-2.00) \pm 0.07$ & 0.46 \\
\hline Age of first genital sex & $\begin{array}{l}18.87(14.00- \\
33.00) \pm 2.89\end{array}$ & $18.47(13.00-24.00) \pm 2.22$ & 0.54 \\
\hline Age of first oral sex & $\begin{array}{l}18.91(13.00- \\
33.00) \pm 3.08\end{array}$ & $18.74(13.00-30.00) \pm 2.58$ & 0.78 \\
\hline Age of first masturbation & $15.60(8.00-30.00) \pm 3.49$ & $15.52(8.00-30.00) \pm 3.09$ & 0.50 \\
\hline Importance of sex & $3.79(1.00-5.00) \pm 0.91$ & $4.03(2.00-5.00) \pm 0.73$ & 0.01 \\
\hline Duration of RS & $7.41(0.50-26.00) \pm 6.20$ & $6.68(0.50-25.00) \pm 5.41$ & 0.48 \\
\hline RS quality & $4.53(1.00-5.00) \pm 0.79$ & $4.45(1.00-5.00) \pm 0.73$ & 0.07 \\
\hline $\mathrm{Nr}$ of lifetime male sexual partners & $0.27(0-6) \pm 0.81$ & $0.29(0-10) \pm 0.99$ & 0.76 \\
\hline $\begin{array}{l}\text { Nr of lifetime female sexual } \\
\text { partners }\end{array}$ & $4.42(3.0-50.0) \pm 6.18$ & $4.7(0.0-40.0) \pm 6.19$ & 0.81 \\
\hline $\begin{array}{l}\text { Satisfaction from a partner as a } \\
\text { lover }\end{array}$ & $3.90(1.00-5.00) \pm 1.01$ & $3.78(1.00-5.00) \pm 0.88$ & 0.05 \\
\hline Partner's attitude toward sex & $4.47(1.00-5.00) \pm 0.77$ & $4.33(1.00-5.00) \pm 0.75$ & 0.02 \\
\hline Attitud's toward sex & $4.47(3.00-5.00) \pm 0.62$ & $4.35(2.00-5.00) \pm 0.57$ & 0.04 \\
\hline Vaginal sex/month & $5.98(0.00-30.00) \pm 6.34$ & $9.50(0.00-30.00) \pm 6.09$ & 0.00 \\
\hline Cuddling/month & $7.66(0.00-50.00) \pm 8.13$ & $6.15(0.00-40.00) \pm 7.35$ & 0.05 \\
\hline Anal sex/month & $0.89(0.00-14.00) \pm 2.41$ & $0.87(0.00-20.00) \pm 2.17$ & 0.28 \\
\hline Oral sex/month & $5.94(0.00-40.00) \pm 6.71$ & $4.65(0.00-81.00) \pm 7.37$ & 0.01 \\
\hline Mutual masturbation/month & $4.06(0.00-25.00) \pm 5.48$ & $3.56(0.00-20.00) \pm 4.12$ & 0.38 \\
\hline Self-masturbation/month & $3.42(0.00-30.00) \pm 5.15$ & $4.27(0.00-103.00) \pm 8.00$ & 0.01 \\
\hline Orgasm/month & $10.46(0.0-100.0) \pm 11.36$ & $8.57(0.00-70.00) \pm 8.98$ & 0.11 \\
\hline nr of sexual events/month & $\begin{array}{l}14.69(0.00- \\
51.00) \pm 38.18\end{array}$ & $\begin{array}{l}10.80(1.00- \\
114.00) \pm 11.39\end{array}$ & 0.20 \\
\hline
\end{tabular}




\begin{tabular}{|llll|}
\hline Satisfying sex/months & $8.92(0.00-40.00) \pm 7.29$ & $9.05(0.00-49.00) \pm 8.22$ & 0.78 \\
\hline Quality of sexual life & $4.37(1.00-5.00) \pm 1.10$ & $4.37(1.00-5.00) \pm 1.01$ & 0.80 \\
\hline Day of cycle & $18.75(0.02-$ & $16.66(0.00-71.00) \pm 10.81$ & 0.81 \\
\hline Length of cycle & $93.33) \pm 15.71$ & $28.83(20.00-90.00) \pm 7.90$ & 0.00 \\
\hline Length of bleeding & $30.76(20.00-$ & & \\
\hline Nr of deliveries & $90.00) \pm 8.21$ & $4.78(1.00-56.00) \pm 4.27$ & 0.00 \\
\hline Duration of contraception use & $5.21(3.00-10.00) \pm 1.15$ & $0.60(0.00-4.00) \pm 1.00$ & 0.02 \\
\hline HADS - anxiety & $0.33(0.00-4.00) \pm 0.73$ & $38.46(3.00-276.0) \pm 50.74$ & 0.81 \\
\hline HADS - depression & $43.92(3.00-$ & & 0.05 \\
\hline BESAQ & $7.69(3.00-16.00) \pm 2.84$ & $6.98(2.00-15.00) \pm 2.50$ & 0.23 \\
\hline CSFQ - pleasure & $3.48(0.00-10.00) \pm 2.84$ & $3.05(0.00-10.00) \pm 2.54$ & 0.00 \\
\hline CSFQ - desire/frequency & $1.00(0.07-3.36) \pm 0.77$ & $1.34(0.00-3.57) \pm 0.80$ & 0.10 \\
\hline CSFQ - desire/interest & $3.90(1.00-5.00) \pm 1.09$ & $3.81(1.00-5.00) \pm 0.83$ & 0.13 \\
\hline CSFQ - arousal/ecitement & $7.06(2.00-10.00) \pm 1.46$ & $7.35(4.00-10.00) \pm 1.08$ & 0.40 \\
\hline CSFQ - orgasm/completion & $9.90(5.00-15.00) \pm 2.43$ & $10.11(3.00-14.00) \pm 2.05$ & 0.07 \\
\hline CSFQ - sum & $10.85(5.00-15.00) \pm 2.00$ & $10.19(3.00-15.00) \pm 1.95$ & 0.01 \\
\hline & $11.12(3.00-15.00) \pm 2.95$ & $10.79(3.00-15.00) \pm 2.20$ & 0.03 \\
\hline
\end{tabular}

* U Mann-Whitney test, BESAQ - Body Exposure during Sexual Activity Questionnaire, CSFQ - Changes in Sexual Function Questionnaire, HADS - Hospital Anxiety and Depression Scale.

\section{Figures}




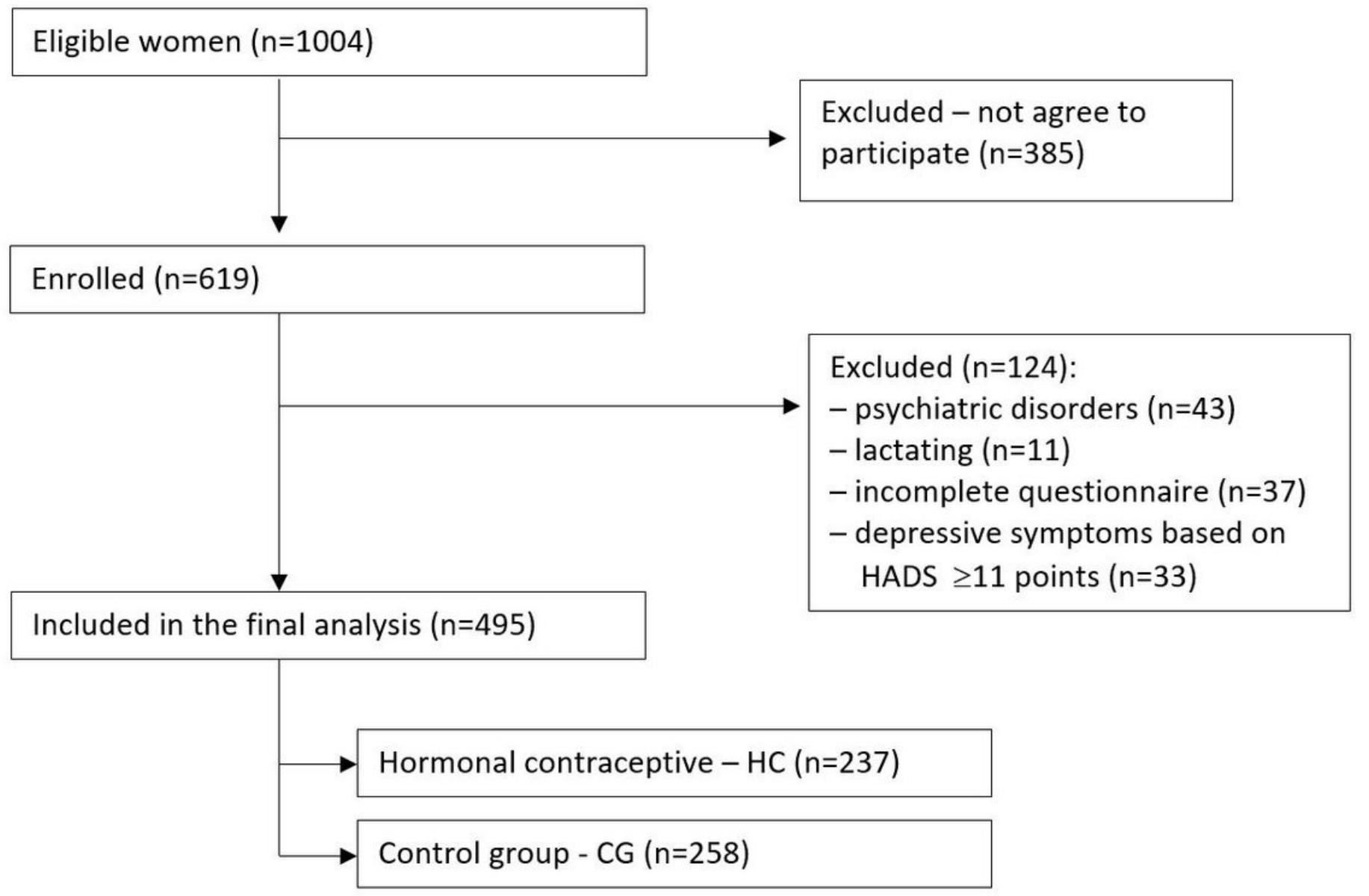

Figure 1

Study flow chart. 


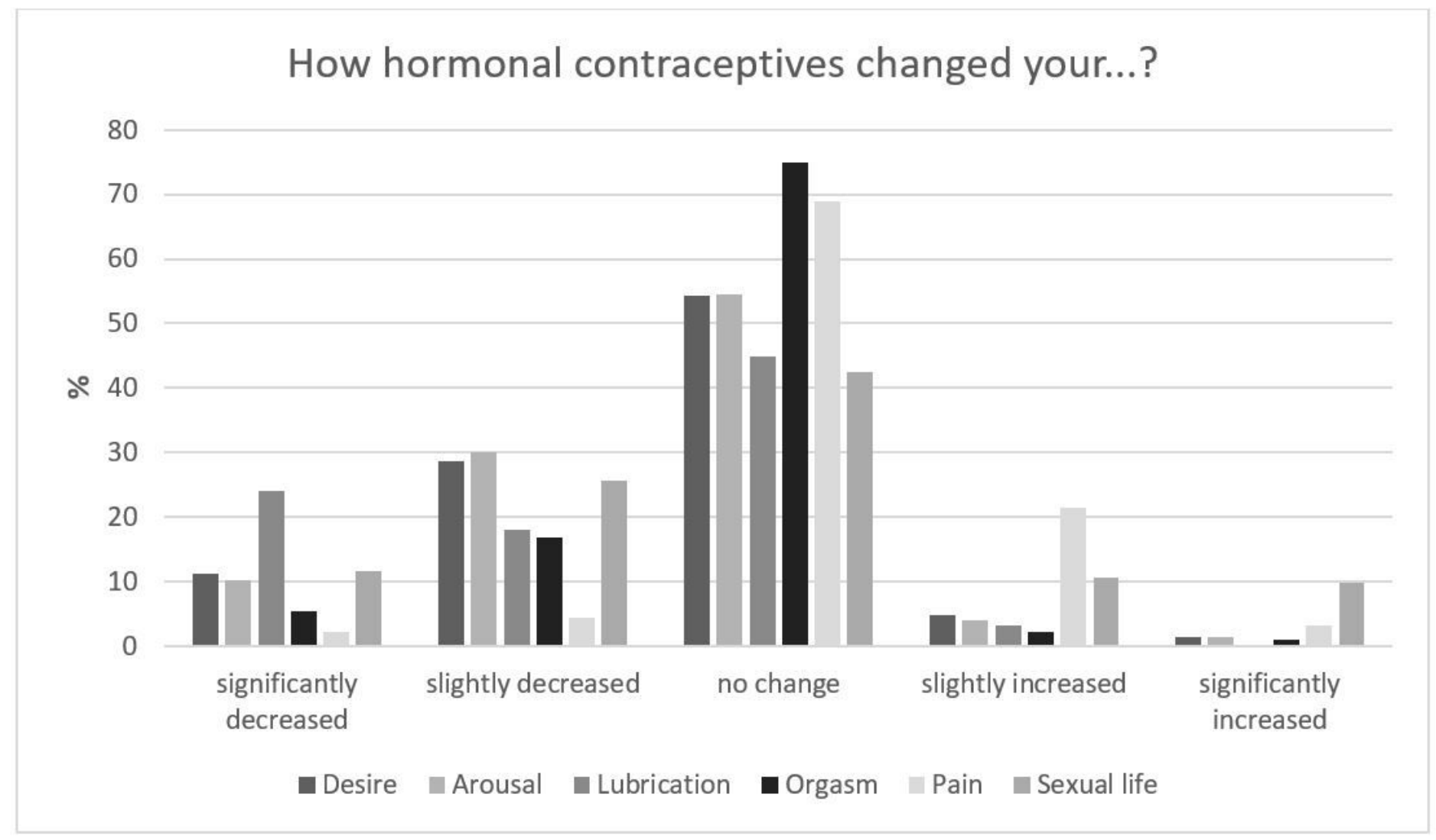

Figure 2

Subjective evaluation of hormonal contraceptives influence of sexual function 